CORRECTION

\title{
Correction: The $\left[\mathrm{PSI}^{+}\right]$Prion Exists as a Dynamic Cloud of Variants
}

\section{The PLOS Genetics Staff}

In the Materials and Methods section, there is an error in the equation under the subheading "Statistical methods". The publisher apologizes for the error. Please view the complete, correct equation here:

$$
\mathrm{S}=\operatorname{sqrt}\left[\mathrm{p}(1-\mathrm{p}) /\left(\mathrm{n}_{1}+\mathrm{n}_{2}\right)\right]
$$

\section{Reference}

1. Bateman DA, Wickner RB (2013) The $\left[P S I^{+}\right]$Prion Exists as a Dynamic Cloud of Variants. PLoS Genet 9(1): e1003257. doi: 10.1371/journal.pgen.1003257 PMID: 23382698

\section{Gopenaccess}

Citation: The PLOS Genetics Staff (2017) Correction: The $\left[\mathrm{PSI}^{+}\right]$Prion Exists as a Dynamic Cloud of Variants. PLoS Genet 13(2): e1006591. doi:10.1371/journal.pgen.1006591

Published: February 3, 2017

Copyright: ๑ 2017 The PLOS Genetics Staff. This is an open access article distributed under the terms of the Creative Commons Attribution License, which permits unrestricted use, distribution, and reproduction in any medium, provided the original author and source are credited. 